\title{
Ĵigo: um editor de objetos de aprendizagem de temas de Ciência, Tecnologia e Sociedade (CTS)
}

Marcelo Leandro Eichler

José Claudio Del Pino

\begin{abstract}
Resumo
No Brasil e no Mundo, é notável a ampliação da produção de conteúdos digitais na forma de objetos de aprendizagem, porém ainda são raros os objetos de aprendizagem construídos tirando proveito das características excepcionais dessa mídia. De acordo com nossa experiência no desenvolvimento de conteúdos digitais um dos pontos críticos é a parte tecnológica e de programação. Neste artigo, descrevemos uma ferramenta simples que pode ser utilizada na produção de objetos de aprendizagem de representações contextuais, visando à educação em ciências através de uma abordagem CTS. Utilizamos essa ferramenta para elaborar um objeto de aprendizagem sobre o tema florestamento de eucaliptos, que é apresentado neste artigo.
\end{abstract}

Palavras-chave: objetos de aprendizagem, educação científica, florestamento.

\section{Abstract \\ Jigo: a generative learning objects (GLO) for Science, Technology and Society (STS) studies}

In worldwide, it's remarkable the large production of digital content like learning objects, but is still rare the learning objects design taking advantages of exceptional characteristics of this media. In accordance with our experience in the development of digital content, a critical point is the technology and programming. In this article, we present a simple tool that can be used in the production of contextual representation's learning objects for science education in a STS approach. An example of learning object about afforestation is presented.

Keywords: learning objects, science education, afforestation.

\section{Introdução}

No Brasil e no Mundo, é notável a ampliação da produção de conteúdos digitais na forma de objetos de aprendizagem, o surgimento de políticas públicas visando a ampliar essa produção e o aparecimento de repositórios para a distribuição desses conteúdos. Há cerca de quinze anos, com o financiamento público de agências oficiais voltadas ao desenvolvimento científico e tecnológico (CNPq, FINEP e FAPERGS), vimos trabalhando com uma equipe interdisciplinar de diferentes IES, em projetos que visam à produção de conteúdos digitais para aprendizagem de ciências. Esses softwares tem sido produzidos sob perspectivas construtivistas para o ensino e aprendizagem de ciências (Eichler, 1999) e unem estratégias de resolução de problema, jogo e 
simulações sob o desenho de cenários, possibilitando ao usuário desenvolver hipóteses sobre os temas estudados, testar tais hipóteses e analisar os seus resultados.

A avaliação de uma importante e interessante experiência (Schibeci et al., 2008) indicou que os objetos de aprendizagem possuem uma variedade de benefícios aos estudantes. Em geral, os estudantes apreciaram a novidade e acharam os objetos de aprendizagem motivadores. Os professores, por sua vez, declararam o aumento dos níveis de concentração, de entusiasmo e de aprendizagem dos alunos quando eles utilizaram os objetos de aprendizagem. Isso porque os estudantes foram motivados a utilizar os objetos de aprendizagem através de desafios, que permitiam que eles explorassem e tivessem controle sobre suas ações, assim entusiasmavam a colaboração entre colegas. Assim, os objetos de aprendizagem levaram os estudantes resistentes às abordagens tradicionais de ensino e com baixos desempenhos acadêmicos a se engajarem em tarefas escolares e de aprendizagem. Nesses casos, observou-se que estudantes considerados problemáticos participaram ativamente das aulas. Também estudantes com pouco ou insuficiente conhecimento de leitura e escrita se engajaram fortemente às atividades, pois os objetos de aprendizagem conferem acesso e interação aos conceitos e conhecimentos por meios mais diversos que os textuais.

Nessa mesma avaliação, do ponto de vista dos projetistas e produtores dos objetos de aprendizagem, evidenciou-se que os conteúdos digitais podem ser aperfeiçoados de várias formas, por exemplo, através da melhor utilização de animações e de elementos visuais e sonoros, reduzindo o tamanho dos textos, indicando instruções de utilização, fornecendo caminhos de navegação e considerando a utilização de estratégias de exploração, resolução de problemas e de jogo.

Por isso, reitera-se a conhecida importância da formação de uma equipe multidisciplinar na qual alunos e professores especialistas em áreas de conhecimentos trabalhem colaborativamente com pedagogos, professores de informática, programadores e web designers. Porém, de acordo com nossa experiência no desenvolvimento de conteúdos digitais, um dos pontos críticos da produção de objetos de aprendizagem é justamente a parte tecnológica e de programação (Eichler e Del Pino, 2001).

Há alguns anos atrás, durante a participação de um evento científico da área de ensino de química, uma professora de ensino médio disse se interessar por nossa proposta de abordagem de conteúdos e temáticas para o ensino de química a partir de estudos de caso ou de estratégias de resolução de problemas, representados em cenários baseados em situações reais. Porém, nos comentava da dificuldade de produzir esses conteúdos digitais, relatando sua experiência na produção de atividades de ensino utilizando desenhos feitos no Paint ou no PhotoShop e cenários produzidos com o auxílio do PowerPoint. Esse questionamento serviu de embrião para o editor de objetos de aprendizagem que buscamos apresentar neste artigo. Tal editor é uma ferramenta simples que pode ser utilizada na produção de objetos de aprendizagem para a educação em 
ciências, utilizando estratégias de solução de problemas e de debates escolares por representação de papéis.

\section{Alguns tópicos da didática das ciências, como subsídio à informática educativa}

A escolha dos temas e o planejamento das atividades a serem apresentados nos objetos de aprendizagem podem seguir orientações das abordagens de ciência, tecnologia e sociedade (CTS) para a educação em ciências. Essa abordagem possui algumas relevantes contribuições na educação científica: i) o nível de abstração pode ser reduzido; ii) o conhecimento pode ser reorganizado ('repackaged', no original), pelos professores; iii) o conhecimento pode ser reconstruído, pelos alunos; e iv) o conhecimento pode ser contextualizado (Gilbert, 1992).

Nesse sentido, por exemplo, as tecnologias relacionadas ao crescimento econômico e à criação de riqueza estão associadas com os principais impactos ambientais, através das demandas que elas têm por energia e por outras matérias-primas. Dessa forma, a tensão entre crescimento econômico e as externalidades ambientais podem ser exploradas pela educação em ciências através de diversos temas, tais como, a acidificação da chuva, o desflorestamento e o aquecimento global (Dillon, 1993).

É possível argumentar que para a solução dos problemas sociais e ambientais contemporâneos é necessária uma geração de cidadãos formados política e cientificamente que não se contentem com o papel da "crítica de escrivaninha" (Hodson, 2003). Assim, sugere-se um currículo de ciências focalizado em assuntos controversos e politizados em diferentes áreas (por exemplo, saúde humana, alimentação e agricultura, recursos energéticos e consumo, e responsabilidade técnica e sociopolítica). Portanto, entende-se que a educação científica para a ação sociopolítica é, inescapavelmente, um exercício de aclaração e mudança de valores, isso porque os valores não podem e não devem ser impostos aos estudantes, mas sua adoção pode ser encorajada.

Acerca do uso de cenários, entende-se que a utilização de histórias para apoiar a apresentação do conteúdo de uma lição é uma estratégia didática comum, descrita muitas vezes como um modo de "familiarizar" a criança ou o jovem com o conteúdo curricular e estabelecer um conhecimento contextualizado. Assim, pode-se usar essa estratégia em software e projetá-los de tal forma que os usuários possam imergir na história e tornar-se protagonista das atividades, sendo possível manipular elementos presentes nos diferentes cenários da interface e interagindo com o conteúdo dos exercícios ou desafios que guiam o estudante através do software (Hinostroza e Mellar, 2001).

Do ponto de vista da psicologia da aprendizagem, sugere-se que a discussão e o diálogo na escola se tornam ferramentas essenciais para a construção do pensamento e da socialização. A 
discussão é uma importante ferramenta que incita a criança ou o jovem à criatividade, ao espírito crítico, à confrontação de pontos de vista diferentes. Assim, o conflito cognitivo, que provoca a diversidade de pontos de vista entre pares, permite que os alunos se questionem, duvidem, problematizem a realidade, proponham soluções, critiquem as alternativas sugeridas e identifiquem os critérios para achar a solução mais coerente. Dessa forma, a discussão e o debate são elementos imprescindíveis de uma pedagogia que pretende desenvolver o pensamento das crianças, a cidadania e a democracia, ou seja, o direito de expressar idéias num espaço coletivo e público, onde se admite o pluralismo (Parrat-Dayan, 2007). Então, acerca do debate de argumentos sobre problemáticas ambientais como, por exemplo, a identificação das fontes e causas de contaminação atmosférica e seus prejuízos sociais, seria possível identificar os atores sociais que participam das controvérsias, tais como o ator social, o ator industrial, o ator científico, o ator político, o ator educativo e o ator moderador (Martínez Pérez, Peñal e Villamil, 2007).

Outra proposta sobre a abordagem de temas controversos indica que é preciso enfatizar que: i) os grupos em sociedade possuem diferentes visões acerca do assunto; ii) os grupos baseiam suas informações em diferentes conjuntos de informações ou interpretam as mesmas informações de modos diversos; iii) as diferentes interpretações podem ocorrer devido às diferentes formas de "ver" o mudo, ou seja, devido às diversas cosmovisões; iv) as diversas comovisões podem ocorrer por que os indivíduos aderem a diferentes sistemas de valor; v) assuntos controversos não podem ser sempre circunscritos à razão, à lógica e ao experimento; e vi) assuntos controversos podem ser resolvidos tornando mais informações disponíveis (Oulton, Dillon e Grace, 2004).

Por fim, fechando a discussão da temática que utilizamos como exemplo no lançamento de nosso editor de objetos de aprendizagem, indica-se que os estudantes devem aprender a interrelação dos conhecimentos técnico, ecológico e sócio-econômico subjacente ao gerenciamento dos recursos naturais e à silvicultura (Vacik et al., 2006). Por isso, deve-se considerar que a tomada de decisão no planejamento da silvicultura envolve aspectos ecológicos, econômicos e sociais, em níveis locais, nacionais e globais. Portanto, entendemos que tal recomendação pode ser seguida através de estratégias didáticas que utilizem o estudo de caso, visando à tomada de decisão, em cenários apresentados em objetos de aprendizagem.

\section{Algumas considerações sobre as características desejáveis em objetos de aprendizagem}

A idéia fundamental subjacente aos objetos de aprendizagem é que seus projetistas instrucionais podem construir pequenos componentes de instrução (relativo ao tamanho de um curso inteiro) que podem ser reusados diversas vezes em diferentes contextos educacionais 
(Wiley, 2000). Mas é preciso notar que a manipulação e a interação são aspectos-chave para a efetiva aprendizagem, pois é através da imersão digital que os usuários constroem seus próprios entendimentos acerca do que está representado, extraindo dali os propósitos e valores educacionais (Littlejohn, Falconer e McGill, 2008).

Assim, a utilização de objetos de aprendizagem apresenta um importante papel de suporte em estratégias ativas de aprendizagem, como aquelas baseadas em estudos de caso, ou em resolução de problemas, ou em formas colaborativas de debates argumentativos. Nessas estratégias, os objetos de aprendizagem promovem estímulo e suporte para a prática de tarefas complexas, não apresentando apenas informações ou guiando um percurso previamente determinado, como na coleção de lições estáticas por algoritmos pré-definidos (Parrish, 2004).

É notório que os objetos de aprendizagem são projetados para suprir sua utilização em diferentes contextos educacionais. Dessa forma, chega-se a propor uma classificação para os objetos de aprendizagem, que conteria objetos de apresentação, objetos de prática, objetos de modelos conceituais, objetos de informação e objetos de representação contextual (Churchill, 2007). Segundo essa classificação, a idéia subjacente aos objetos de representação contextual é permitir aos estudantes a exploração de algum cenário realístico, onde ele possa coletar dados, normalmente com o propósito de resolução de problemas ou investigação. Os exemplos envolvem temas muitos diversos, como a atividade vulcânica, as condições climáticas, os poluentes atmosféricos, as formas de vida em grandes profundidades oceânicas e o relato da opinião das pessoas acerca desses assuntos ou de outros.

Geralmente, utiliza-se a representação contextual de algum lugar imaginário ou inacessível aos estudantes, devido a, por exemplo, sua distância, no tempo ou no espaço, ou ao perigo envolvido em seu acesso e exploração, ou a escala muito pequena ou muito grande para a coleta de dados, ou a necessidade de instrumentos sofisticados para tal, entre outros. Um exemplo é a representação contextual acerca da qualidade da água. No objeto de aprendizagem produzido, os alunos podem coletar dados acerca dos fatores que afetam a qualidade da água em um lago imaginário, apresentado como cenário. Tais dados podem ser usados em uma atividade de resolução de problemas que sugere aos alunos agirem como ambientalistas, investigando a situação e propondo uma solução para o problema na forma de um relatório para uma agência de proteção ambiental.

Ou seja, essa idéia é muito similar aquilo que vimos produzindo (Eichler et. al. 2003 e 2005), inspirados no trabalho de David Whisnant (1984 e 1992). Porém, a questão tecnológica e a programação continuam sendo pontos sensíveis à produção dos objetos de aprendizagem.

Nesse ponto, é bastante relevante o conceito de um editor de objetos de aprendizagem (Generative Learning Objects - GLO, no original), baseado na separação entre o projeto de aprendizagem e a instanciação da fachada do objeto de aprendizagem (Morales, Leeder e Boyle, 
2005). O conceito-chave de um editor de objetos de aprendizagem é separar a estrutura profunda (o projeto pedagógico ou projeto de aprendizagem) da estrutura de superfície (a fachada ou a apresentação) dos objetos de aprendizagem. A fachada do objeto de aprendizagem é vista com uma realização particular de um projeto de aprendizagem subjacente. Isso apresenta muitas vantagens. Centra-se a maior atenção sobre o que é mais importante, a qualidade do projeto de aprendizagem que será apoiada pelo objeto digital, como abordado na secção anterior. Uma vez que a fachada do objeto é gerada em uma série de passos, muitas variantes podem ser produzidas com o mesmo projeto. Além disso, uma vez que os objetos de aprendizagem são divididos em componentes básicos e estruturais, torna-se fácil identificar e modificar componentes individuais. Assim, nos editores de objetos de aprendizagem, utiliza-se um modelo de reuso para a estrutura de superfície, o que está próximo da engenharia de software orientada a objeto. Isso produz diversas vantagens, entre elas: i) focaliza a atenção na qualidade do projeto de aprendizagem, que é o cerne do objeto de aprendizagem; e ii) apresenta o fundamento para uma marcante ampliação da produção de objetos de aprendizagem.

A criação de um editor de objetos de aprendizagem é dividida em duas amplas partes, a construção de um gabarito para os objetos de aprendizagem (Learning Object Template, no original) e a posterior adição dos conteúdos específicos. Esse gabarito, ou modelo de objeto de aprendizagem, contém a estrutura profunda ou o projeto de aprendizagem. Uma vez criado o gabarito, tutores (professores ou alunos, por exemplo) podem adicionar diferentes conteúdos específicos, produzindo diversos objetos de aprendizagem, adaptados aos propósitos de suas áreas de conhecimento, que depois de revisados e analisados por avaliadores podem ser publicados e distribuídos pela Internet.

Porém, justamente devido aos poucos exemplos, é preciso e urgente criar ferramentas amigáveis para suportar esse processo de criação dos objetos de aprendizagem. A ferramenta que apresentamos na próxima secção, Ĵigo, é um editor de objetos de aprendizagem que contém um gabarito para a produção de representações contextuais.

\section{Um editor de objetos de aprendizagem: Ĵigo}

O objetivo de Ĵigo é propiciar um ambiente de criação e de utilização de objetos de aprendizagem que permitam a professores e alunos buscar a apresentação e a discussão de temas relacionados ao meio ambiente. Em Ĵigo, a estrutura de fachada, de apresentação, pode ser editada. Como estrutura profunda nós estabelecemos a utilização de dois projetos pedagógicos ou de aprendizagem, apoiados em cenários: resolução de problemas e debate escolar. Portanto, Ĵigo é um gabarito, uma template para esses tipos de atividade pedagógica. Para o nome desse gabarito e do seu editor foi adotado o termo 'jigo', do esperanto, que sugere idéias de jogo, quebra-cabeça, jogo de paciência e puzzle, por exemplo. 
A seguir, descrevemos as principais etapas de edição da estrutura de apresentação dos objetos de aprendizagem. Nesse sentido, usamos como exemplo a temática do florestamento de eucaliptos (Hasse, 2006; Vaz, 2012).

No editor de objetos de aprendizagem, após o cadastramento do usuário, aparece uma tela semelhante à Figura 1, onde são inseridas as informações (título, assunto, descrição, palavras-chave e escolha da paisagem) que descrevem o objeto de aprendizagem planejado.

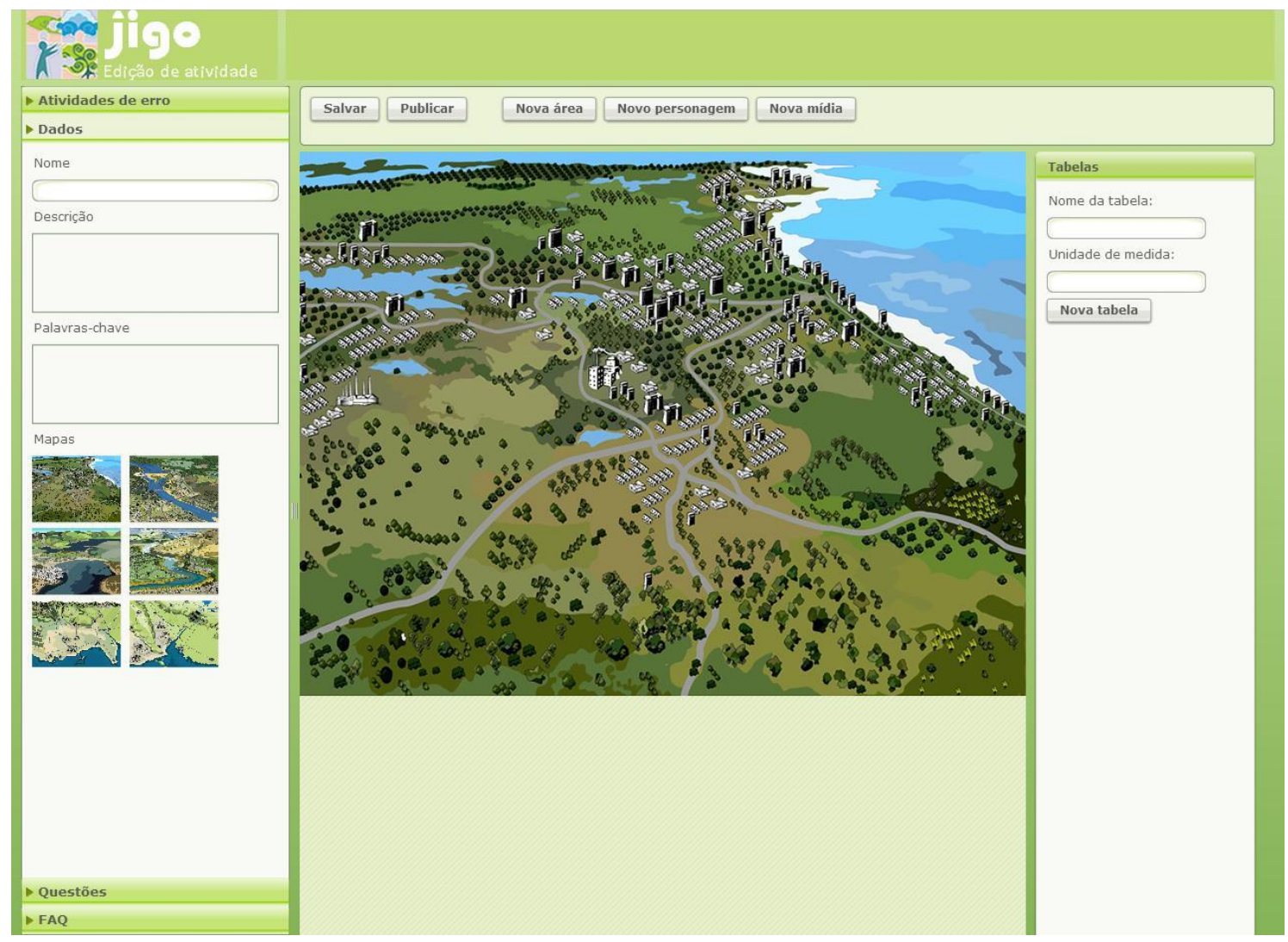

Figura 1 - Tela inicial de edição dos objetos de aprendizagem.

Na parte lateral direita do editor são apresentadas as ações de edição e de criação do objeto de aprendizagem, que é composta de cinco etapas: i) descrição da atividade; ii) áreas e dados; iii) personagens e mídias; iv) questões da atividade; e v) FAQ da atividade.

Na primeira etapa, de descrição do objeto de aprendizagem, o usuário (por exemplo, um professor) deve escolher entre as ilustrações oferecidas que possibilitam a ambientação e a contextualização das atividades que se propõe a desenvolver. Atualmente são oferecidas 6 paisagens de regiões urbana, rural, litorânea e montanhosa.

O primeiro objeto de aprendizagem produzido através de Ĵigo tem como assunto a indústria de papel e celulose e os impactos ambientais e sociais da silvicultura. Então, nessa primeira etapa, indicou-se que: 
"Conforme as atuais preocupações com o desenvolvimento econômico sustentável, o eucalipto tornou-se simultaneamente alvo de ataques raivosos dos defensores do equilíbrio ambiental e objeto de defesa apaixonada dos adeptos da silvicultura comercial. Por coincidência, a polêmica sobre o avanço do eucalipto em bioma predominantemente campestre (como os pampas gaúcho e platino) ocorre exatamente no mesmo momento em que se discute a validade do desmatamento da Amazônia para o plantio de lavouras de grãos (como a soja, por exemplo). Nesse sentido, o eucalipto vem assumindo um lugar como substituto de madeiras tropicais cuja exploração é cada vez mais difícil por razões geográficas e ambientais. Assim, neste objeto de aprendizagem, utiliza-se um cenário de florestamento de eucaliptos como representação contextual visando ao debate escolar (por exemplo, através de jogo de representação de papéis) e a reflexão em torno da pertinência de determinadas escolhas econômicas e seus impactos nas comunidades terrestres. Nesse sentido, você terá que tomar a decisão quanto ao florestamento de eucaliptos em uma área de pradaria, ou seja, em uma região de pastagem e produção agropecuária. No objeto de aprendizagem podem ser lidos depoimentos de personagens que apresentam as diversas versões acerca do assunto, podem ser coletadas informações sobre a qualidade do solo $e$ podem ser vistos vídeos e imagens que ilustram a temática. Caso necessário, pode ser acessada uma aba de ajuda, elaborada através de perguntas e respostas. Além disso, há um questionário a ser respondido após a utilização do objeto de aprendizagem".

Na segunda etapa, são atribuídas tabelas de dados relacionados às diferentes áreas da paisagem. Em um outro exemplo, se um professor pretende criar um cenário visando ao debate sobre os agrotóxicos no meio ambiente, ele pode escolher uma paisagem de uma microrregião de transição entre o rural e o urbano, alimentar o banco de dados com as unidades de concentração de agrotóxicos (p.ex., organofosforados ou carbamatos) e estipular diferentes concentrações para diversas áreas da paisagem. Nesse exemplo, durante a utilização do objeto de aprendizagem, os alunos, poderiam vir a pesquisar a concentração de agrotóxicos em diferentes locais da paisagem. Esse tipo de atividade é similar aquela que desenvolvemos no software Carbópolis (www.iq.ufrgs.br/aeq/carbopolis; Eichler e Del Pino, 2000). Novamente, os dados de pesquisas acadêmicas são úteis na elaboração das atividades.

No caso do objeto de aprendizagem sobre o florestamento de eucaliptos, inserimos dados sobre o índice de acidez $(\mathrm{pH})$ do solo em diferentes regiões do cenário, no mapa ilustrativo, conforme a Figura 2. Foram inseridas seis áreas, em partes do cenário que ilustram campos ou pradarias, em que foram disponibilizados os dados de $\mathrm{pH}$ do solo e se há na área o florestamento 
de eucalipto. Na parte superior do cenário foram incluídas duas áreas em que há florestamento de eucalipto e o pH dos solos é entre 5,0 e 5,1. Nas outras áreas não há florestamento de eucalipto e o pH dos solos é entre 6,0 e 6,1. Esses dados foram obtidos conforme os trabalhos de Jackson et. al. (2003), Jobbágy e Jackson (2003 e 2004) e Kiehl (1979).

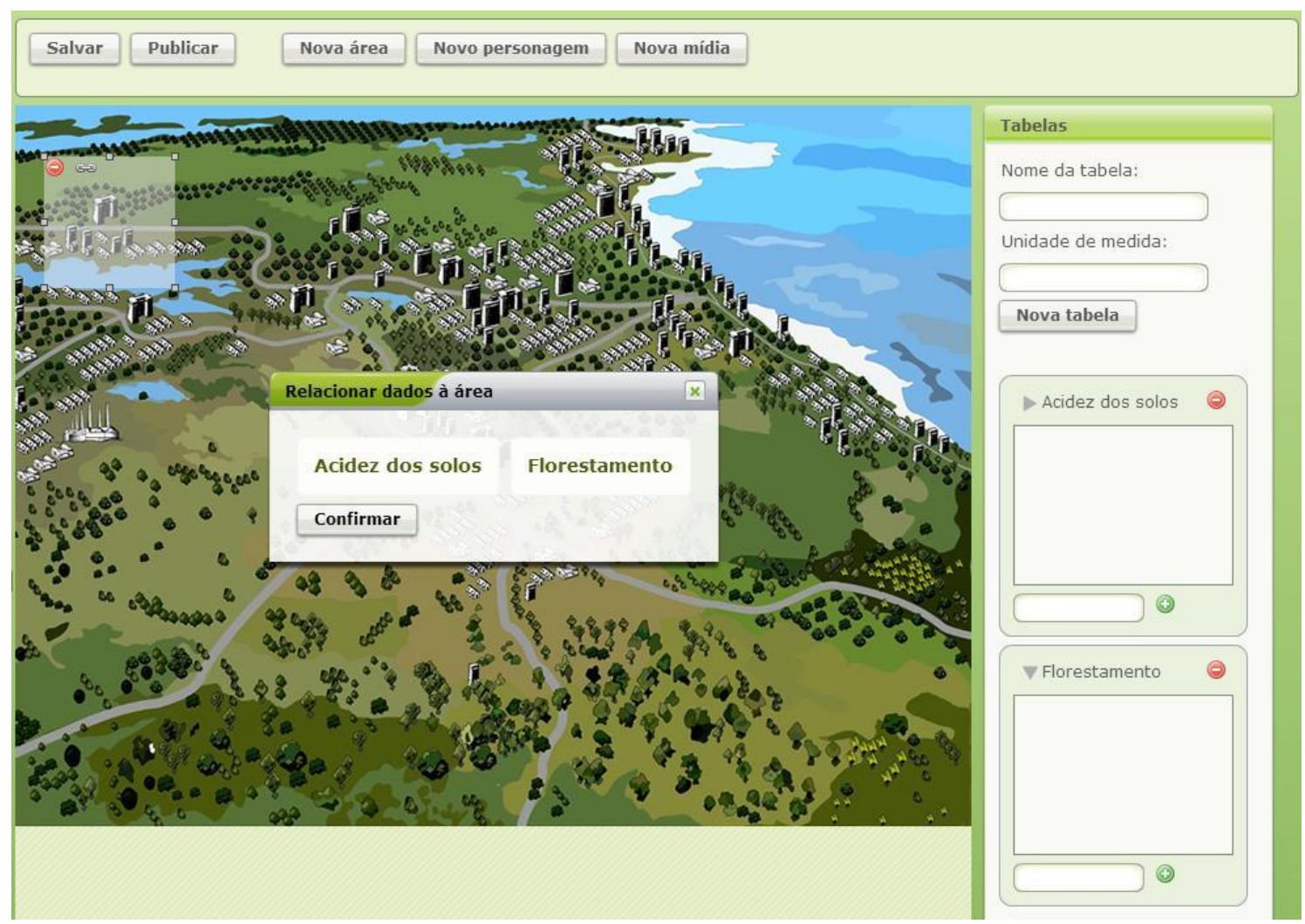

Figura 2- Tela de inserção de áreas, tabelas e dados no cenário escolhido anteriormente.

Em relação à descrição do problema ambiental associada ao florestamento de eucaliptos, conforme Kiehl (1979), o pH indica, de certa forma, a saúde dos solos. O caráter de acidez ou alcalinidade dos solos é um importante fator na produção agrícola - florestal, influindo na disponibilidade de nutrientes às raízes das plantas, propiciando condições favoráveis ou de toxidez; concorre, igualmente, para favorecer o desenvolvimento de microorganismos que operam transformações úteis para melhorar as condições do solo, como também podem concorrer para dar meio propício a microorganismos causadores de doenças às plantas. Os solos que têm o pH entre 5,8 e 7,5 tendem ser livres de problemas do ponto de vista do crescimento de plantas. Abaixo do $\mathrm{pH}$ 5, poderá haver deficiência de elementos Ca (cálcio), $\mathrm{Mg}$ (magnésio), P (fósforo), Mo (molibdênio), B (boro), ou toxidez de Al (alumínio), Mn (manganês), Zn (zinco) e outros metais pesados. Por outro lado, conforme 
Jackson et. al. (2003), pesquisas em áreas de florestamento têm mostrado que, em regiões onde há plantações de eucaliptos entre 10 e 100 anos, nota-se a diminuição de cerca de 1 unidade de pH, em média, e a baixa troca de íons de cálcio na superfície do solo. A acidificação dos solos dos pampas, sob as plantações de eucalipto, é da mesma intensidade de áreas altamente industrializadas afetadas por chuva ácida. A combinação de pesquisas de campo, envolvendo a síntese de mais de 600 observações, com a modelagem climática e econômica mostrou uma substancial perda no fluxo dos cursos d'água e aumento da acidificação e salinização dos solos sob florestamento. Quanto à acidez, de forma geral, em 98 de 114 casos, o florestamento resultou na diminuição média de 0,3 unidades de pH. Em um quarto dos casos, o declínio foi maior, entre 0,5 e 1,6 unidades de $\mathrm{pH}$.

$\mathrm{Na}$ terceira etapa, são inseridas imagens e personagens que servem para ilustrar os diferentes pontos-de-vista de um assunto. Nessa etapa, o usuário poderá editar um determinado número de personagens (escolhendo gênero, etnia e vestimentas, por exemplo) que serão inseridos em diferentes locais da paisagem, conforme Figura 3.

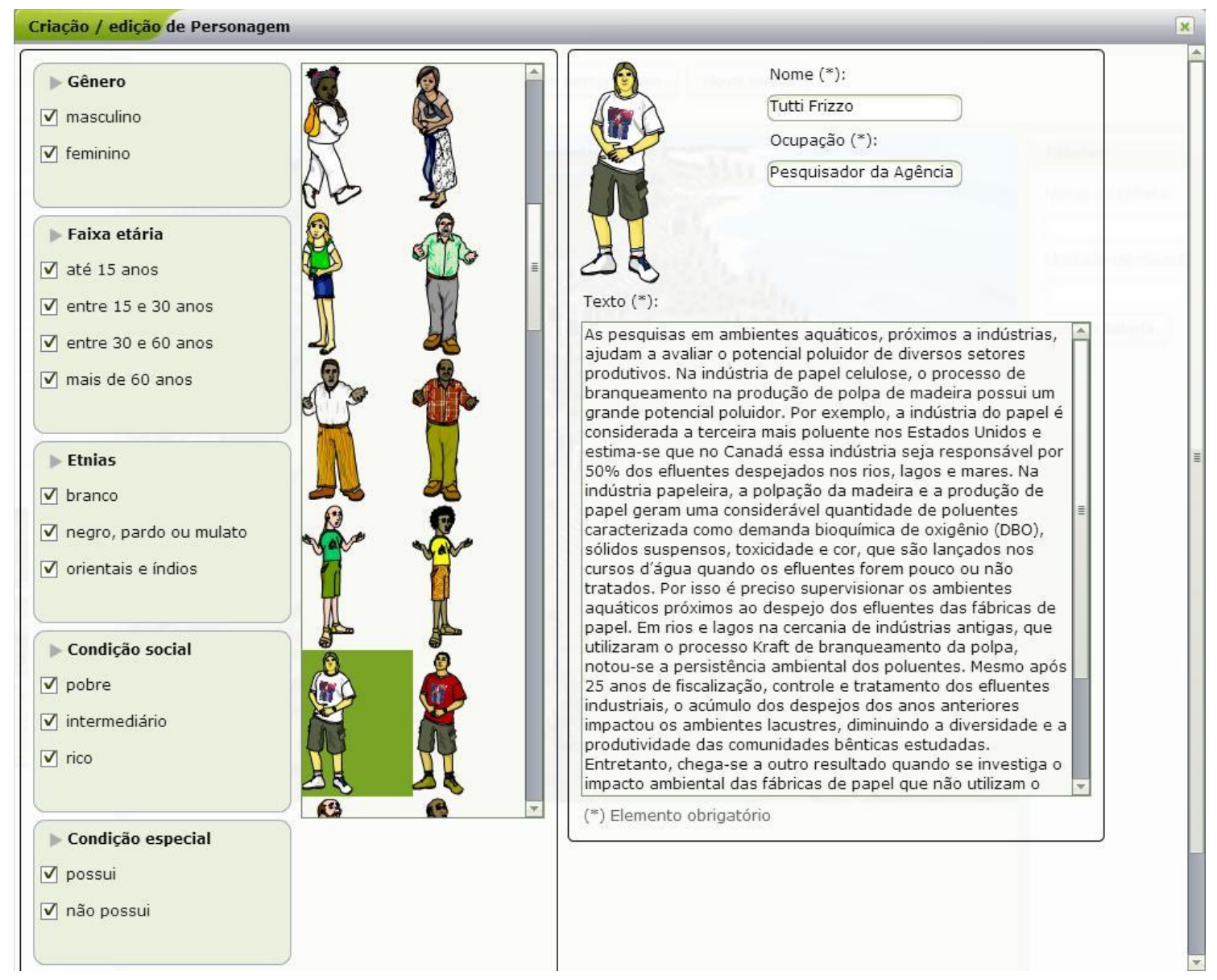

Figura 3- Tela de escolha dos personagens para inserção nos objetos de aprendizagem. 
Nesse tipo de atividade, os usuários devem indicar os depoimentos desses personagens em relação à temática que esteja em discussão. Por exemplo, se um professor pretende criar um cenário visando ao debate sobre os alimentos geneticamente modificados, pode escolher uma paisagem de uma macrorregião, depois solicitar que os alunos montem os personagens e que indique os depoimentos que os personagens fariam sobre o tema em debate. A montagem inicial desse cenário serve de suporte para os jogos de representação de papéis, conforme atividade similar que desenvolvemos no software Cidade do Átomo (www.iq.ufrgs.br/aeq/cidadedoatomo; Eichler, Junges e Del Pino, 2006).

No caso do objeto de aprendizagem sobre o florestamento de eucaliptos, utilizamos diversas opiniões apresentadas em Hasse (2006), informações econômicas e ambientais relatadas por Hilgemberg e Bacha (2003) e imagens e argumentos reportados por Vaz (2008a, 2008b e 2008c), entre outras referências. Os sete personagens criados, bem como seus depoimentos, desenvolvidos a partir da literatura concernente ao tema em questão, são apresentados a seguir:

1) Tutti Frizzo (Pesquisador da Agência de Proteção Ambiental): As pesquisas em ambientes aquáticos, próximos a indústrias, ajudam a avaliar o potencial poluidor de diversos setores produtivos. $\mathrm{Na}$ indústria de papel celulose, o processo de branqueamento na produção de polpa de madeira possui um grande potencial poluidor. Por exemplo, a indústria do papel é considerada a terceira mais poluente nos Estados Unidos e estima-se que no Canadá essa indústria seja responsável por $50 \%$ dos efluentes despejados nos rios, lagos e mares. Na indústria papeleira, a polpação da madeira e a produção de papel geram uma considerável quantidade de poluentes caracterizada como demanda bioquímica de oxigênio (DBO), sólidos suspensos, toxicidade e cor, que são lançados nos cursos d'água quando os efluentes forem pouco ou não tratados. Por isso é preciso supervisionar os ambientes aquáticos próximos ao despejo dos efluentes das fábricas de papel. Em rios e lagos na cercania de indústrias antigas, que utilizaram o processo Kraft de branqueamento da polpa, notou-se a persistência ambiental dos poluentes. Mesmo após 25 anos de fiscalização, controle $e$ tratamento dos efluentes industriais, o acúmulo dos despejos dos anos anteriores impactou os ambientes lacustres, diminuindo a diversidade e a produtividade das comunidades bênticas estudadas. Entretanto, chega-se a outro resultado quando se investiga o impacto ambiental das fábricas de papel que não utilizam o processo de branqueamento na produção de polpa de madeira. Nesses casos, os ensaios de 
laboratório e as pesquisas de campo indicam que não é possível evidenciar efeitos adversos à biota do ambiente aquático nas proximidades da indústria de papel que não utiliza o processo Kraft de branqueamento. (Felder et. al., 1998; MacDonald et. al., 1998; Pokhrel e Viraraghavan, 2004; Sibley et. al., 2000).

2) Izabel Green (Médica, toxicóloga e ativista de Organização Não Governamental Verde): As tecnologias de produção de papel utilizadas nos países em desenvolvimento são diferentes daquelas que são usadas nos países desenvolvidos. Enquanto na Europa e nos Estados Unidos as atuais tecnologias de branqueamento do papel são ecologicamente corretas, pois não produzem efluentes com substâncias organocloradas, a maior parte das indústrias de papel em países em desenvolvimento, como no Brasil e na Índia, está ainda baseada em tecnologias convencionais de branqueamento, que fazem uso de altas quantidades de cloro elementar. O gás cloro e os compostos de cloro utilizados no branqueamento do papel produzem numerosos compostos organoclorados. A maior preocupação é com os compostos que são altamente tóxicos e de baixo peso molecular, pois esses são persistentes à degradação ambiental. Esses compostos químicos são conhecidos com o nome de dioxinas. Esse é um nome comum para duas famílias de compostos químicos, os dibenzo-pdioxinas policloradas (são 75 compostos diferentes) e dibenzofuranos policlorados (135 compostos). Nos efluentes da indústria papeleira, entre essas 210 diferentes dioxinas, dois são os compostos mais preocupantes do ponto de vista da toxicologia, o 2,3,7,8-TCDD $\begin{array}{llll}\text { (tetraclorodibenzo-p-dioxina) } \quad e & o & 2,3,7,8-T C D F\end{array}$ (tetraclorodibenzofurano). Essas dioxinas são concentradas nos sedimentos dos ambientes aquáticos (lagos e rios, principalmente), ocasionando efeitos duradouros na biota aquática. Essas substâncias, também, sofrem bioacumulação e bioconcentração, que eventualmente pode afetar a saúde dos seres humanos através da cadeia alimentar. Dessa forma, a exposição humana às dioxinas provém quase que exclusivamente $d a$ ingestão alimentar, especialmente de carne, peixes e laticínios (Kim Oanh et. al., 1999).

3) Masao Onda (Professor universitário na área de ecologia): As plantações de eucalipto afetam a qualidade dos solos em pradarias $e$ savanas. Algumas pesquisas relatam uma rápida salinização do solo e 
das águas subterrâneas em regiões de florestamento de eucalipto na pradaria úmida do Pampa argentino. Os solos sob plantações de eucaliptos apresentaram, também, aumento da acidez, quando comparados com o solo da pradaria. Em regiões onde há plantações de eucaliptos entre 10 e 100 anos, notou-se a diminuição de cerca de 1 unidade de pH, em média, e a baixa troca de íons de cálcio na superfície do solo. A acidificação dos solos dos pampas, sob as plantações de eucalipto, é da mesma intensidade de áreas altamente industrializadas afetadas por chuva ácida. Porém, em um artigo mais abrangente, publicado na prestigiosa revista Science, mostrou-se que as estratégias de seqüestro de carbono privilegiam a plantação de árvores sem considerar completamente suas conseqüências ambientais. A combinação de pesquisas de campo, envolvendo a síntese de mais de 600 observações, com a modelagem climática e econômica mostrou uma substancial perda no fluxo dos cursos d'água e aumento da acidificação e salinização dos solos sob florestamento. As plantações de árvores apresentam maior demanda de água do que as pradarias, as savanas e as terras agrícolas, que tipicamente também possuem aumento na demanda de nutrientes. Essa demanda modifica a química do solo, afetando sua fertilidade e resistência. Observa-se uma diminuição da concentração de cálcio, magnésio e potássio, devido à duplicação da concentração de sódio em muitas amostras de solo. Quanto à acidez, de forma geral, em 98 de 114 casos, o florestamento resultou na diminuição média de 0,3 unidades de $\mathrm{pH}$. Em um quarto dos casos, o declínio foi maior, entre 0,5 e 1,6 unidades de pH (Jackson et. al., 2003; Jobbágy e Jackson, 2003 e 2004).

4) João da Mata (Engenheiro florestal e pesquisador da indústria papeleira): As plantações de eucalipto em larga-escala e industrial são um fenômeno das quatro últimas décadas. As maiores áreas plantadas com eucalipto estão no Brasil, na África do Sul, na Espanha e em Portugal. O Brasil é o maior produtor mundial de polpa de eucalipto. As plantações de Eucalyptus Grandis, principalmente, fornecem mais de 15 milhões de $m 3$ de polpa de celulose a baixos custos. $O$ crescimento da madeira se dá entre 5 e 10 anos e fornece um material uniforme, opaco e com boa claridade, que pode ser utilizado na produção de papéis brancos para a impressão e cópia. A demanda por esse produto está aumentando e cerca de metade do comércio internacional de polpa de madeira branqueada é originada dos eucaliptos. Pode-se 
dizer que, em geral, todas as atividades da indústria papeleira são conduzidas de acordo com os mais altos princípios de tecnologia, de qualidade e do desenvolvimento sustentável, que significa a promoção do desenvolvimento econômico e social em harmonia com a natureza. Para assegurar a produção sustentável de madeira, a indústria investe em pesquisa, desenvolvimento e inovação para melhorar suas florestas, seus processos de produção de polpa de madeira e seus produtos. Visando à melhoria da qualidade, as companhias do setor desenvolvem e adaptam tecnologias, especialmente aquelas relacionadas ao cultivo do eucalipto e ao manejo do solo (Campinhos Jr., 1999).

5) Salita Pardi (Economista de fundação pública de pesquisa aplicada): Desde a metade dos anos 1980, os movimentos sociais tem tido uma profunda influência sob a indústria papeleira. Na primeira metade do Século $X X$, surgem os primeiros avanços tecnológicos nessa indústria, através do advento do processo Kraft de polpação, incluindo a utilização do gás cloro para o branqueamento da polpa. Porém, devido à pressão dos ativistas ambientais e dos legisladores, a utilização do cloro elementar foi eliminada do processo Kraft de polpação $e$ branqueamento. Isso ocorreu nos países do norte da Europa, onde os ambientalistas são institucionalmente fortes, com diversos membros no parlamento e em ministérios, devido à participação de membros de partidos vinculados à causa ecológica em coalizões de governo. Por volta de 1991, os líderes da indústria papeleira declararam o gás cloro banido do processo de fabricação do papel, nos Estados Unidos e na Europa. Utilizando expressões como "adaptando-se às novas demandas do mercado", os industriais foram influenciados e cederam ao ativismo ambiental e apressaram inovações nas tecnologias de polpação e branqueamento. Assim surgiram duas alternativas: a substituição do cloro elementar pelo dióxido de cloro no branqueamento da celulose, gerando o processo ECF (elementar chlorine free, no original; livre de cloro elementar), ou o branqueamento com peróxido de hidrogênio, originando o processo TCF (totally chlorine free, no original, totalmente livre de cloro). A utilização das tecnologias ECF e TCF, entretanto, resulta em uma produtividade muito menor. A tecnologia TCF tem sido adotada amplamente nos países nórdicos (Finlândia, Noruega e Suécia, por exemplo) e é a favorita dos mercados europeus, enquanto que as 
indústrias estadunidenses utilizam o processo ECF. As empresas norteamericanas argumentam que os benefícios adicionais da tecnologia TCF não compensam o investimento extra. Trata-se de um caso típico de um jogo não-cooperativo no qual uma empresa não adota o processo TCF simplesmente porque as demais não o farão. No Brasil, constata-se que há empresas que ainda produzem celulose standard (branqueada com gás cloro) para atender o mercado interno ou a determinados clientes menos exigentes do ponto de vista ambiental, mas bastante sensiveis em relação a preço. As diferentes proporções de produção da celulose standard, ECF e TCF entre as empresas refletem os distintos mercados atendidos pelas empresas produtoras de celulose (Fig, 2007; Hilgemberg e Bacha, 2003; Sonnenfeld, 2002).

6) Vero Claríssimo (Biólogo e paisagista): As florestas plantadas são parte da paisagem em muitas regiões do mundo. A plantação de florestas fornece lenha e forragem no Senegal, polpa de celulose no Brasil, tábuas na Nova Zelândia, proteção às bacias hidrográficas no Nepal e paisagens estéticas na Escócia e na Dinamarca. Essas florestas contribuem para a prosperidade econômica e a potencial sustentabilidade das comunidades humanas. As florestas plantadas provêm madeira, forragem, habitats para a vida selvagem, proteção para microbacias hidrográficas, lugares recreativos, experiências estéticas e condições ecológicas para muitas outras florestas. A pressão humana sobre as florestas nativas continua a crescer, por razões que vão desde a necessidade de lenha até o desejo de preservar ecossistemas antigos. As florestas plantadas, manejadas intensiva ou extensivamente, são essenciais para o futuro e o presente de nossas sociedades e culturas. Devido as espécies utilizadas $e$ ao desenvolvimento genético, o eucalipto se tornou, atualmente, a espécie florestal mais plantada no mundo. No final do Século XVIII, o botânico francês Charles Louis De Brutelle chamou de Eucalyptus uma árvore australiana. Naquela época, não se percebeu o potencial do eucalipto como uma importante fonte de produtos florestais. A madeira era difícil de serrar e tratar, então era comumente considerada como fonte de lenha. Porém, as razões para plantar eucaliptos mudaram muito através do tempo. Hoje em dia, o eucalipto fornece madeira para tábuas, esteio, dormente e moirões, polpa de celulose, chapas de compensado, carvão, óleos essenciais, mel, taninos, sombra e proteção à fauna (Boyle, 1999; Turnbull, 1999). 
7) José Pretto (Agrônomo da Secretaria de Agricultura): $\mathrm{O} p H$ indica, de certa forma, a saúde dos solos. O caráter de acidez ou alcalinidade dos solos é um importante fator na produção agrícola - florestal, influindo na disponibilidade de nutrientes às raízes das plantas, propiciando condições favoráveis ou de toxidez; concorre, igualmente, para favorecer o desenvolvimento de microorganismos que operam transformações úteis para melhorar as condições do solo, como também podem concorrer para dar meio propício a microorganismos causadores de doenças às plantas. Os solos que têm o pH entre 5,8 e 7,5 tendem ser livres de problemas do ponto de vista do crescimento de plantas. Abaixo do $\mathrm{pH} 5$, poderá haver deficiência de elementos $\mathrm{Ca}$ (cálcio), Mg (magnésio), P (fósforo), Mo (molibdênio), B (boro), ou toxidez de Al (alumínio), Mn (manganês), Zn (zinco) e outros metais pesados. A presença de $\mathrm{pH}$ entre 8,0 e 8,5 indica a ocorrência de carbonato de cálcio e/ou magnésio livres e baixas disponibilidades dos elementos P, Mn, Zn e Cu (cobre) (Kiehl, 1979).

Quanto às imagens e os vídeos inseridos no objeto de aprendizagem eles podem ser obtidos em sítios que disponibilizam documentos digitais de distribuição livre. Em relação às imagens (fotografias, por exemplo), nos objetos de aprendizagem foram utilizadas imagens de paisagens naturais e fotografias de indústria de papel e celulose obtidas no sítio Flickr.com, que é repositório de imagens digitais. Por sua vez, os vídeos utilizados podem ser obtidos de empresas jornalísticas que utilizam mídias digitais ou de repositórios de vídeos em formato digital como o YouTube.com. Na Figura 4 pode ser vista a imagem do módulo de uso de Ĵigo, após a inclusão dos diversos depoimentos de personagens e das mídias digitais (imagens e vídeos) realizadas no módulo de edição. 


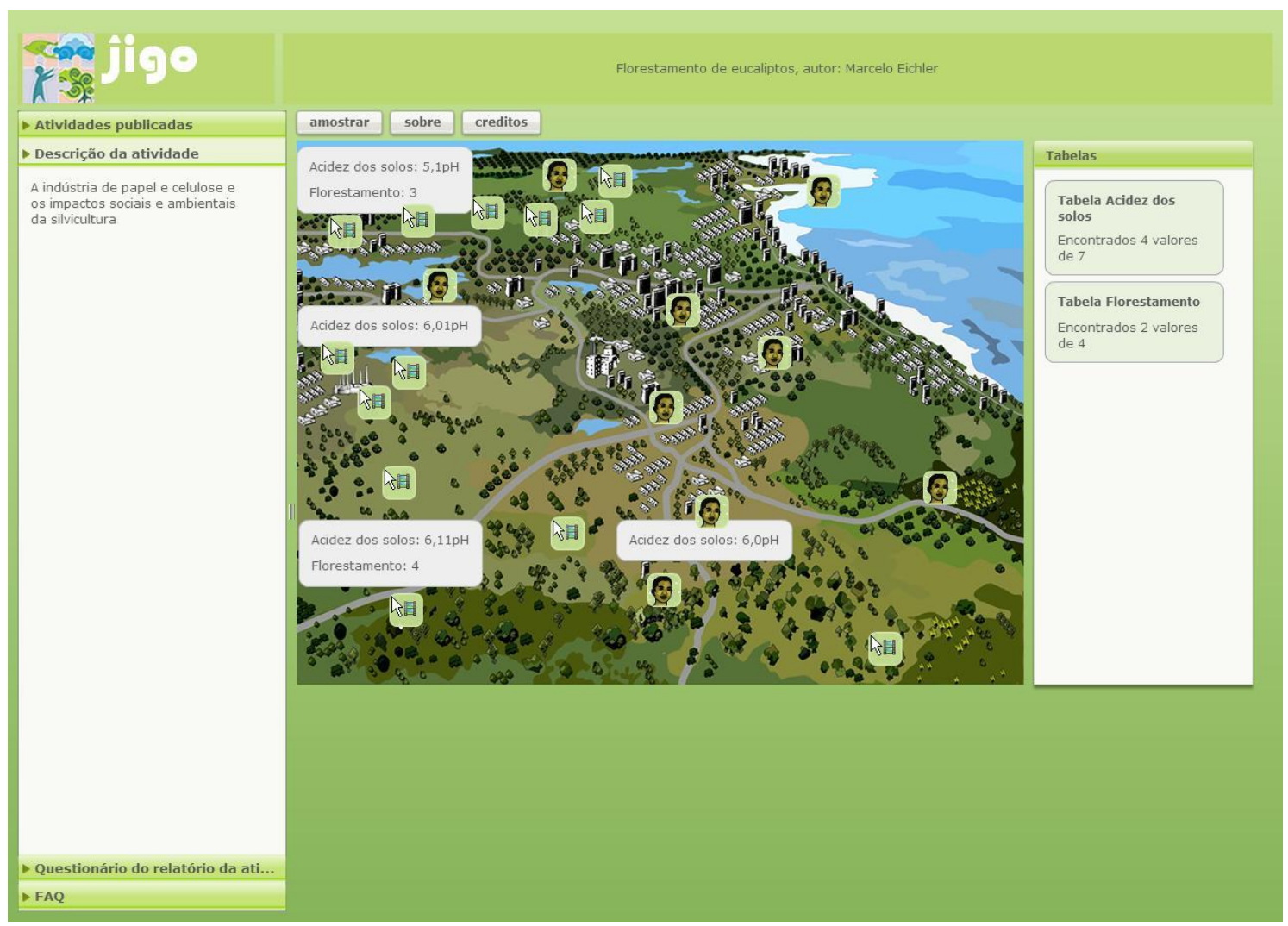

Figura 3-Módulo de uso de Jigo, com o objeto de aprendizagem sobre florestamento.

A terceira e quarta etapas consistem na elaboração dos textos de apoio à utilização do objeto de aprendizagem, seja na forma de questionários que indiquem uma conclusão para as atividades, seja a partir de um conjunto de perguntas e respostas que servem para dirimir as dúvidas dos usuários acerca da utilização do objeto de aprendizagem planejado ou do conteúdo apresentado. No caso do objeto de aprendizagem que vimos apresentando, foi criada uma F.A.Q. que contém os seguintes itens:

Como eu devo usar esse objeto de aprendizagem?

A idéia é que você explore livremente o objeto de aprendizagem. Acesse as diferentes informações, na forma de texto, ou em imagens e vídeos. Analisando, somando e comparando essas informações você terá melhores condições de tomar uma decisão com relação a essa temática.

O que eu devo fazer após concluir o questionário ao final da atividade?

Pergunte para seu(sua) professor(a). Provavelmente o e-mail dele(a) foi informado, então envie uma mensagem eletrônica com os conteúdos de seu 
questionário e verifique se não haverá outro tipo de avaliação ou utilização da atividade.

Onde posso obter mais informações sobre os assuntos que são aqui apresentados e sobre os quais eu pouco conheço ou quero me informar melhor?

Essa ferramenta foi basicamente concebida utilizando informações retiradas da Internet. Nesse sentido, indicamos algumas importantes fontes de informação para uso escolar, como a Wikipedia e o YouTube.

Além disso, em relação à finalização do objeto de aprendizagem sobre o florestamento de eucaliptos, imaginamos a utilização de uma estratégia didática envolvendo o debate escolar (por exemplo, através de um jogo de representação de papéis). Nesse sentido, prevemos as seguintes perguntas a serem respondidas pelos alunos ao final da utilização do objeto de aprendizagem:

1. Como você pôde observar, na parte inferior do mapa, existe a indicação de uma região em que pode ocorrer o florestamento de eucalipto. Você concorda que essa área seja utilizada para a plantação de eucaliptos visando à produção de polpa de celulose e papel? Escreva uma redação em que estejam presentes os argumentos que sustentam sua decisão.

2. Uma vez que há a possibilidade de desenvolver um debate acerca dessa temática, que outros indivíduos, grupos ou organizações você acha que concordam com sua opinião?

3. Na mesma linha da questão anterior, que outros indivíduos, grupos ou organizações você acha que discordam de sua posição?

4. Nem sempre as pessoas estão de acordo em temas polêmicos, assim, quais são alguns argumentos contrários a sua posição?

5. Por fim, como você poderia responder a esses argumentos?

\section{Conclusões}

Neste artigo para além do propósito de apresentar nosso editor de objetos de aprendizagem, chamado Ĵigo, buscamos apresentar um gabarito (o projeto pedagógico ou projeto de aprendizagem) para a produção de objetos de aprendizagem de representações contextuais. Com o aporte de proposições da didática das ciências e da informática educativa, sugerimos que a utilização de objetos de aprendizagem apresenta um importante papel de suporte em estratégias 
ativas de aprendizagem, como aquelas baseadas em estudos de caso ou em resolução de problemas (visando à tomada de decisão), ou em formas colaborativas de debates argumentativos (como nos debates escolares por representação de papéis). Nesse sentido, indicamos que a idéia subjacente aos objetos de representação contextual é permitir aos estudantes a exploração de algum cenário realístico, onde ele possa coletar dados, normalmente com o propósito de resolução de problemas ou tomada de decisão.

Em relação à escolha dos assuntos para os objetos de aprendizagem de representações contextuais, indicamos que a escolha dos temas e o planejamento das atividades a serem apresentados nos objetos de aprendizagem podem seguir orientações das abordagens de ciência, tecnologia e sociedade (CTS) para a educação em ciências. No decorrer do artigo, particularizamos as funcionalidades do editor de objetos de aprendizagem em relação ao tema da silvicultura, a partir dos debates subjacentes ao florestamento de eucaliptos. Entendemos que esse tipo de abordagem é relevante para propostas didáticas ativas para o ensino técnico ou superior, em especial em disciplinas de ciências naturais ou aplicadas, que tangenciam assuntos relacionados ao meio ambiente e que possam ser apresentados a partir de representações de paisagens. Assim, procuramos apresentar a abordagem das questões acerca do florestamento de eucaliptos a partir de uma ampla revisão bibliográfica com o intuito de demonstrar como uma temática CTS pode ser profícua para a apresentação de conceitos científicos, inclusive, no âmbito do ensino especializado.

Porém, do ponto de vista da tecnologia da informação, entendemos que é necessário atualizar aspectos tecnológicos e de linguagem de programação do editor de objetos de aprendizagem, que foi produzido com tecnologia Adobe Air e Adobe Flash, que conforme anúncio da empresa desenvolvedora não terá solução de continuidade. Assim, faz-se necessário produzir esse editor em uma nova plataforma tecnológica, como a HTML5.

Por fim, ao encerrar este artigo, é preciso dizer que, posteriormente, conforme realizamos com Carbópolis (Eichler e Del Pino, 2006), após uma ampla divulgação junto aos sistemas de ensino, pretendemos verificar como esse tipo de material didático é efetivamente utilizado em contextos escolares, principalmente em relação às estratégias didáticas utilizadas pelos(as) professores(as).

\section{Agradecimentos}

À FINEP, pelo financiamento concedido, que permitiu a elaboração do editor de objetos de aprendizagem.

\section{Referências}


BOYLE, J.R. Planted forests: views and viewpoints. New Forests, v. 17, p. 5-9, 1999.

CAMPINHOS JR., E. Sustainable plantations of high-yield Eucalyptus trees for production of fiber: the Aracruz case. New Forests, v. 17, p. 129-143, 1999.

CHURCHILL, D. Towards a useful classification of learning objects. Educational Technology Research and Development, v. 55, p. 479-497, 2007.

DILLON, P.J. Technological education and the environment. International Journal of Science Education, v. 15, n. 5, p. 575-589, 1993.

EICHLER, M.L. Uma abordagem construtivista para a aprendizagem de ciências com o uso do computador. Informática na Educação Teoria e Prática, v. 2, n.2, p. 55-64, 1999.

EICHLER, M. L. ; DEL PINO, J. C. Carbópolis, um software para educação química. Química Nova na Escola, v. 11, p. 10-12, 2000.

EICHLER, M.L. \& DEL PINO, J.C. Algumas reflexões sobre o desenvolvimento de um projeto de informática educativa, em época de ajuste fiscal. Tecnologia Educacional, v. 30, n. 154, p. 57-69, 2001.

EICHLER, M.L. \& DEL PINO, J.C. Ambientes virtuais de aprendizagem: desenvolvimento e avaliação de um projeto em educação ambiental. Porto Alegre: Editora da UFRGS, 2006.

EICHLER, M.L., JUNGES, F., DEL PINO, J. C. Cidade do Átomo, um software para o debate escolar sobre energia nuclear. A Física na Escola, v. 7, n.1, p. 17-22, 2006.

EICHLER, M.L., GONÇALVES, M.R., SILVA, F.O.M., JUNGES, F.; \& DEL PINO, J.C. Virtual learning environments designed in Brazil. Educational Technology, v. 43, p. 58-60, 2003.

EICHLER, M.L., XAVIER, P.R., ARAÚJO, R.C., FORTE, R.C., \& DEL PINO, J.C. Carbopolis: a Java technology-based free software for environmental education. Journal of Computers in Mathematics and Science Teaching, v. 24, p. 43-72, 2005.

FELDER, D.P.; D'SURNEY, S.J.; RODGERS JR., J.H.; DEARDORFF, T.L. A comprehensive environmental assessment of a receiving aquatic system near an unbleached kraft mill. Ecotoxicology, v. 7, p. 313-324, 1998.

FIG, D. Questioning CSR in the Brazilian Atlantic Forest: the case of Aracruz Celulose S.A. Third World Quarterly, v. 28, n. 4, p. $831-849,2007$.

GILBERT, J.K. The interface between science education and technology education. International Journal of Science Education, v. 14, n. 5, p. 563-578, 1992.

HASSE, G. Eucalipto: histórias de um imigrante vegetal. Porto Alegre: Já Editores, 2006.

HILGEMBERG, E.M. \& BACHA, C.J.C. A indústria brasileira de celulose de mercado e as pressões ambientais. Estudos Econômicos, v. 33, n. 1, p. 143-180, 2003. 
HINOSTROZA, J.E.; \& MELLAR, H. Pedagogy embedded in educational software design: report of a case study. Computers \& Education, v. 37, p. 27-40, 2001.

HODSON, D. Time for action: science education for an alternative future. International Journal of Science Education, v. 25, n. 6, p. 645-670, 2003.

JACKSON, R.B.; JOBBÁGY, E.G.; AVISSAR, R.; ROY, S.B.; BARRET, D.J.; COOK, C.W.; FARLEY, K.A.; LE MAITRE, D.C.; MCCARL, B.A.; MURRAY, B.C. Trading water for carbon with biological carbon sequestration. Science, v. 310, n. 5756, p. 1944-1947, 2003.

JOBBÁGY, E.G. \& JACKSON, R.B. Patterns and mechanisms of soil acidification in the conversion of grasslands to forests. Biogeochemistry, v. 64, p. 205-229, 2003.

JOBBÁGY, E.G. \& JACKSON, R.B. Groundwater use and salinization with grassland afforestation. Global Change Biology, v. 10, p. 1299-1312, 2004.

KIEHL, J.E. Manual de edafologia. São Paulo: Agronômica Ceres, 1979.

KIM OANH, N.T.; BENGTSSON, B.-E.; REUTERGÅRDH, L.B.; HOA, D.T.; BERGQVIST, P.-A.; BROMAN, D.; ZEBÜHR, Y. Persistent organochlorianes in the effluentes from a chlorine-bleached Kraft integrated pulp and paper mill in Southeast Asia. Archives of Envionmental Contamination and Toxicology, v. 37, p. 303-309, 1999.

LITTLEJOHN, A.; FALCONER, I.; \& MCGILL, L. Characterising effective eLearning resources. Computers \& Education, v. 50, p. 757-771, 2008.

MACDONALD, R.W.; IKONOMOU, M.G.; PATON, D.W. Historical inputs of PCDDs, PCDFs, and PCBs to a British Columbia Interior Lake: The effect of environmental controls on pulp mill emissions. Environmental Science and Technology, v. 32, p. 331-337, 1998.

MARTíNEZ PÉREZ, L. F.; PEÑAL, D. C.; \& VILLAMIL, Y. M. Relaciones ciência, tecnologia, sociedad y ambiente a partir de casos simulados: uma experiência em la enseñanza de la química. Ciência $\boldsymbol{\&}$

Ensino, 1 (Número especial), 2007.2 Disponível em: <http://prc.ifsp.edu.br/ojs/index.php/cienciaeensino/>. Acessado em: 09/05/2014.

MORALES, R, LEEDER, D. and BOYLE, T. (2005) A case study in the design of generative learning objects (GLOs): applied statistical methods GLOs. Proceedings of ED-MEDIA 2005 (World Conference on Educational Multimedia, Hypermedia and Telecommunications). Montreal, Canada, Junho-Julho de 2005, pp 302-310. Disponível em: < http://www.editlib.org/noaccess/20381/>. Acessado em: 09/05/2014.

OULTON, C.; DILLON, J. \& GRACE, M.C. Reconceptualising the teaching of controversial issues. International Journal of Science Education, v. 26, n. 4, p. 411-423, 2004.

PARRAT-DAYAN, S. A discussão como ferramenta para o processo de socialização e para a construção do pensamento. Educação em Revista, v. 45, p. 13-23, 2007.

R. B. E. C. T., vol 7, núm. 1, jan-abr.2014 ISSN - 1982-873X 
PARRISH, P.E. The trouble with learning objects. Educational Technology Research and Development, v. 52, n. 1, p. 49-67, 2004.

POKHREL, F. \& VIRARAGHAVAN, T. Treatment of pulp and paper Mill wastewater - a review. Science of the Total Environment, n. 333, p. 37-58, 2004.

SCHIBECI, R.; LAKE, D.; PHILLIPS, R.; LOWE, K.; CUMMINGS, R. \& MILLER, E. Evaluating the use of learning objects in Australian and New Zealand schools. Computers \& Education, v. 50, p. 271283, 2008.

SIBLEY, P.K.; DIXON, D.G.; BARTON, D.R. Impact of bleached kraft pulp mill effluent on benthic community structure in relation to environmental factors. Journal of Aquatic Ecosystem Stress and Recovery, v. 7, p. 229-246, 2000.

SONNENFELD, D.A. Social movements and ecological modernization: the transformation of pulp and paper manufacturing. Development and Change, v. 33, p. 1-27, 2002.

TURNBULL, J.W. Eucalypt plantations. New Forests, v. 17, p. 37-52, 1999.

VACIK, H.; WOLFSLEHNER, B.; SPÖRK, J.; \& KORTSCHAK, E. The use of COCOON in teaching silviculture. Computers \& Education, v. 47, p. 245-259, 2006.

VAZ, L. Sanguessugas do Brasil. São Paulo: Geração Editorial.

WHISNANT, D.M Scientific exploration with a microcomputer: simulations for nonscientists. Journal of Chemical Education, v. 61, n. 7, p. 627-629, 1984.

WHISNANT, D.M. A role-playing exercise using a computer simulation. Journal of Chemical Education, v. 69, n. 1, p. 42-43, 1992.

WILEY, D. A. Connecting Learning Objects to instructional design theory: a definition, a metaphor, and a taxonomy. In D. A. Wiley (Ed.), The instructional use of Learning Objects, 2000. Disponível em: <http://reusability.org/read/chapters/wiley.doc>. Acessado em: 09/05/2014.

Marcelo Leandro Eichler é Licenciado em Química (UFRGS) e Doutor em Psicologia do Desenvolvimento (UFRGS). Atualmente é professor adjunto do Departamento de Química Inorgânica da Universidade Federal do Rio Grande do Sul (UFRGS), docente permanente do Programa de Pós-graduação Educação em Ciências: Química da Vida e Saúde (UFRGS) e docente colaborador do Programa de Pós-graduação Educação Científica e Tecnológica (UFSC). Também é bolsista de Produtividade de Desenvolvimento Tecnológico e Extensão Inovadora do CNPq.

José Claudio Del Pino é Licenciado em Química (PUCRS), Doutor em Engenharia de Biomassa (UFRGS) e Pós-Doutor em Ensino Superior pela Universidade de Aveiro (Portugal). Atualmente 
é professor do Programa de Pós-graduação Educação em Ciências: Química da Vida e Saúde (UFRGS) e Programa de Pós-graduação Ensino (UNIVATES). Também é bolsista de Produtividade em Pesquisa do CNPq. 